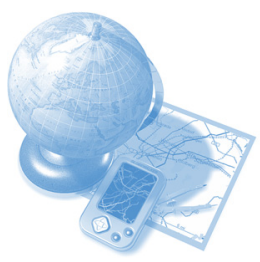

Stephen J Swithenby Centre for Open Learning of Mathematics, Science, Computing and Technology The Open University Milton Keynes MK14 6AT s.j.swithenby@open.ac.uk

The project has demonstrated repeatedly the value of a process of self-audit of teaching practice within a theoretically and empirically valid framework

\section{Formative Assessment in Science Teaching}

\begin{abstract}
The Formative Assessment in Science project was funded by HEFCE as part of the Fund for the Development of Teaching and Learning Programme. Its work was completed in March 2006. The project was centred on a strong collaboration between the Open University and Sheffield Hallam University, but also involved 20 other universities in action learning activities aimed at improving formative assessment. The project partners used a conceptually and empirically based framework of conditions which, if met, lead to assessment that drives learning. The projects were diverse and the many positive assessment changes achieved demonstrate that the approach of a framework based analysis and careful evaluation can be successful in improving the student experience. I will summarise some of the main conclusions of the project. One concerns the creation of written feedback that promotes learning rather than merely justifying marks. A second covers the effective use of peer assessment. Finally, I will outline the tools that the project has generated. These will remain available for others to undertake similar reform activities.
\end{abstract}

\section{Introduction}

The Formative Assessment in Science Teaching (FAST) project was funded by HEFCE via the Fund for the Development of Teaching and Learning (FDTL). The project, which formally ended in summer 2006, was concerned with the way assessment affects student learning. It was not about measuring learning but about supporting learning. The key feature of FAST was the combination of a strong conceptual analysis and a very practical and 'down-to-earth' engagement with the reality of teaching and learning. FAST's work is documented in a Web based report that will appear in autumn 2006 and in many publications.

The FAST approach to improving assessment relied on a conceptual framework of eleven conditions under which assessment supports learning ${ }^{1}$. These conditions were drafted using a combination of theoretical arguments and observations of effective practice. They highlight the importance of student engagement and feedback. (see Table 1).

Armed with this framework, the project adopted an action research approach. We worked with nearly 30 project leaders who had responsibility for teaching specific science modules. In each case, the project leader analysed the way they assess the module against the criteria for the assessment to support learning, and identified possible beneficial changes. In many cases, they implemented and evaluated the effects of these changes, thus closing the quality improvement circle. This process was aided by using investigative tools developed by FAST, including:

- an Assessment Experience Questionnaire that generates information about student perceptions of assessment,

- a Perceptions of Feedback Questionnaire,

- a Written Feedback Coding Tool that helps the teacher to identify the sort of feedback that is being given,

- a number of structured interview templates.

All of these tools have been used in several projects and are available on the present website at www.open.ac.uk/science/fdtl/. 


\begin{tabular}{|c|c|}
\hline Engagement & Feedback \\
\hline $\begin{array}{l}\text { 1. Assessed tasks capture sufficient student time and } \\
\text { effort. } \\
\text { 2. These tasks distribute student effort evenly across } \\
\text { topics and weeks. } \\
\text { 3. These tasks engage students in productive learning } \\
\text { activity. } \\
\text { 4. Assessment communicates clear and high } \\
\text { expectations to students. }\end{array}$ & $\begin{array}{l}\text { 5. Sufficient feedback is provided, both often enough and in } \\
\text { enough detail. } \\
\text { 6. The feedback is provided quickly enough to be useful to } \\
\text { students. } \\
\text { 7. Feedback focuses on learning rather than on marks or the } \\
\text { students themselves. } \\
\text { 8. Feedback is linked to the purpose of the assignment and } \\
\text { to criteria. } \\
\text { 9. Feedback is understandable to students, given their } \\
\text { sophistication. } \\
\text { 10. Feedback is received by students and attended to. } \\
\text { 11. Feedback is acted upon by students to improve their } \\
\text { work or their learning. }\end{array}$ \\
\hline
\end{tabular}

The project was led by the Open University and Sheffield Hallam University, who together pursued 18 individual assessment improvement projects. A further 15 projects were led by colleagues within partner universities, including Abertay Dundee, Bath, Birkbeck, Brunel, Durham, East Anglia, Hull, Keele, Liverpool John Moores, Napier, Surrey and Wolverhampton. The details of these projects are available on the Website. The titles in the Appendix indicate the scope of the projects.

Given the scale of the work supported by FAST, it is not possible to offer a comprehensive account of what we have learnt. Here is my personal set of issues that have made me stop and think (with reference to the criteria and conditions listed in Table 1).

\section{Self-audit works}

The project has demonstrated repeatedly the value of a process of self-audit of teaching practice within a theoretically and empirically valid framework. Even the most experienced teacher can pursue a strategy that is well executed but misguided. For example, my own institution is very fortunate in having a large group of Associate Lecturers who mark and provide feedback on written assignments. The quality of this feedback is widely recognised. However, its value is hugely diminished if we don't set assignments that allow the student to respond to the feedback (Condition 11) and if the feedback is late in arriving (Condition 6). Too often this has been the case.

Many other examples of such blindness have been uncovered by the FAST projects.

\section{Students must understand the guidance we offer}

In spite of the introduction of specific learning outcomes and a great deal of energy expended in drafting feedback, there are many examples of students not understanding what we are saying (Condition 9) because of the use of what is in effect jargon. For example, what would a student understand by 'More critical analysis' or '59/100 - excellent'?
A number of teachers have had a great deal of success in improving learning by scheduling sessions for explicit discussion about what is expected of students. This tactic has been a feature of the sister FDTL project, Effective Feedback Enhanced Learning, led by Nottingham Trent University.

\section{Feedback must feed forward}

Too often, we draft feedback that is aimed at justifying the marks we have awarded rather than guiding future learning. In many cases too, we focus on content rather than skills. The result tends to be that feedback is valued but is not valuable in that it is not acted upon. There are many tactics that can be used to overcome this. We can learn how to focus the feedback and make it feedforward. We can decouple marks and feedback (Condition 7) so that the student must attend to the feedback in order to evaluate their success. Perhaps most crucially, we can prepare assessment tasks that scaffold learning with the feedback from one task feeding into future tasks.

\section{Self and peer assessment are under-used}

Perhaps the most striking gains have been achieved by teachers who have introduced robust mechanisms for self and peer assessment. The latter is particularly interesting. Peer assessment requires students to think about the performance criteria and, through their grading of their peer's work, to focus again on the material covered (Criteria 3 and 4). Very pertinently, it allows students to receive additional feedback without the teacher having to do more work or, where it substitutes for teacher marking, less work. Although peer assessment is by no means new, it is controversial with both students and staff. Some students object and assert that the marking will be inaccurate and that 'marking is your job'. Such objections can be dealt with by introducing it carefully with a fully explained rationale and by including appeal mechanisms. A useful introduction to self and peer assessment has been published by the Higher Education Academy Centre for Biosciences ${ }^{2}$ 


\section{Computer based assessment has great potential} Although computer based assessment (CBA) is widely used, recent technological advances and increased pedagogical skills suggest substantial further opportunities in both summative and formative roles. Several FAST projects demonstrate that CBA can be used to diagnose areas of need and to check on progress. In these roles, the flexible availability of CBA (Criterion 2) and the promptness of feedback (Condition 6) are highly relevant. In several cases, the CBA reported by the FAST projects is traditional in style with a heavy reliance on multiple choice questions and a concentration on testing knowledge and understanding. However, other projects involve CBA of greater complexity. One of the most interesting developments is the incorporation of tasks that require the student to construct knowledge, eg build a set of apparatus or a molecule. In this way, assessment and learning are connected. A further area of interest is the generation of tailored feedback, again demonstrated in some FAST projects. The key to unlocking the potential of CBA may well lie in the construction of useful and available item banks. Recent Higher Education Academy Physical Science Centre initiatives aimed at filling this gap.

The above list reflects my personal judgements on FAST activities. Developments are continuing. There are several ongoing projects and initiatives that are aimed at improving the effectiveness of formative assessment, eg the Centre for Open Learning of Maths, Science, Computing and Technology, the Centre for Excellence in Assessment for Learning and the Scottish Funding Council initiative, Re-engineering Assessment Practices in Scottish Higher Education.

For further information about FAST, please contact one of the following.

Open University

Stephen Swithenby: s.j.swithenby@open.ac.uk or

Valda Stevens: v.a.m.stevens@open.ac.uk

Sheffield Hallam University

John Mills: j.mills@shu.ac.uk

or

Chris Glover: c.j.glover@shu.ac.uk

\section{References}

1. Gibbs, G. and Simpson, C. Does your assessment support your students' learning? Learning and Teaching in Higher Education (on-line), 1(1), 3-31 (2004-5). Available online at http://www.glos.ac.uk/adu/clt/lathe/ issue $1 /$ index.cfm (accessed 7/8/06)

2. Orsmond, P., Self- and Peer-Assessment: Guidance in Practice in the Biosciences, Centre for Bioscience, Higher Education Academy, Enhancing Learning Series, Eds: Stephen Maw, Jackie Wilson and Heather Sears, (2004). Available on http://www.bioscience.heacademy.ac.uk/ publications/tbel/selfpeerassess.htm\#fulltxt

\section{Appendix}

The following list includes those FAST projects that are complete and documented. Other projects are complete but the reports are not yet agreed. The list is split loosely into four groups that are concerned with; the nature and mode of feedback, the impact of course structures, progress checks, and the use of computers. The placing of the projects within these categories is somewhat arbitrary as several involve multiple interventions and aspirations.

- Removing the grade from a formative assessment.

- Reformatting feedback on assignments to enhance effectiveness.

- Towards an optimised feedback scheme in the teaching of second year physical chemistry to Forensic and Analytical and Pharmaceutical Science students.

- An investigation to find if articulating learning outcomes explicitly changes the nature of tutor feedback comments on assignments.

- Feedback that feeds forward.

- Early feedback to students as they complete assignments.

- Returning formative feedback: traditional versus electronic approaches.

- The timeliness and relevance of feedback to students in a DNA Technology module.

- Perceptions of Formative Assessment in a Fourth Year Project Module.

- A study using formative assessment feedback in physiology and pharmacology to encourage engagement.

- Using assessment within course structure to drive student engagement with the learning process.

- Improving feedback in a level 5 Pathology module.

- A scenario-based approach to Analytical Science with rapid feedback on progress.

- Driving formative assessment through summative means.

- The effect on student learning of replacing assessment of a topic by formal written examination with a continuously assessed problem assignment.

- In-Course Assessment of undergraduate chemistry using 'seen' class tests.

- Millstones or Milestones?

- Supporting Transition.

- Spot checks in Chemistry.

- A Study into the use of computer aided assessment to enhance formative assessment during the early stages of undergraduate chemistry courses.

- A short course assessment strategy with formative impact.

- The formative effectiveness of an online practice assessment.

- Automated Assessed Tutoring

- Automated Assessed Tutoring - Financial derivatives.

- Assessing the effectiveness of feedback in online objective tests in Mechanics.

- Evaluating the effects of frequent computer-based assessment on the study habits of mature, part-time students in biology. 